\title{
Measuring the Accuracy of Forecasting Using Integrated VAR models
}

\author{
Niveen Ali Mohammed Elmor* \\ *Assistant Lecturer at Statistics, Mathematics and Insurance Department \\ Faculty of Commerce -Port Said University
}




\section{Abstract}

This study addressed the problem of prediction integration. Different weighting methods are applied to different VAR models. Some economic time series such as unemployment rates, economic growth rates and the general government expenditure series are used to study their effect on each other through the use of VAR, VARX and SVAR models. An evaluation of the integration between predections is presented. The results showed that the combined models prediction is better than normal models. The BICW method is the best combining method.

\section{Keywords :}

Combining forecasts - Vector Autoregressive - Weights method 


\section{الملخص}

تتمثل مشكله الدراسه فى أن عملية الامج بين التنبؤات تعتبر عمليه إحصائيه معقده ولذلك وجب على الاراسه إستخدام طريقه الاوزان المختلفه لتطبيق عملية الامج على النماذج الناتجه من إستخدام أسلوب متجه الانحدار الذاتى بأساليب مختلفه ـ وتتمثل أيضا مثكله البحث فى عرض بعض السلاسل الزمنيه الإقتصاديه كمعدلات البطاله ومعدلات النمو الإقتصادى وسلسلة الإنفاق الحكومى العام وذلك لدراسه إياً من السلاسل له تأثير على الأخر وذلك من خلال إستخدام أسلوب متجه الإندار الذاتى VAR وأسلوب متجه الإندار الذاتى المدمج ـ أثبتت الدراسة إحصائيا أن الإنفاق العام الحكومي يعتبر متغير أساسي داخلي في التحليل الأحصائي وذلك لما له تأثير علي النموذج الاحصائي وثبت أيضا قدره النماذج المدمجة على التنبؤ أفضل من النماذج العادية بالطرق التقليدية كما أوضحت الدراسة أن طربقه الأوزان BICW تعتبر من أفضل طرق الدمج المستخدمه لامج التنبؤات .كما توصي الدراسة بأستخدام طرق الاوزان وذلك لتحسين القدرة التنبؤية للسلاسل الزمنية وذلك لأنها تعطي أفضل النتائج.كما توصي الدراسة بأستخدام طريقة BICW للامج وذلك لأنها تعطي نماذجها المدمجة أفضل قدرة تنبؤية . 


\section{Introduction}

Multiple forecasts of the same variable are often available to decision makers. It can reflect differences in forecasters' subjective judgments due to differences in modeling approaches. In this case, two forecasters may well arrive at very different views depending on the maintained assumptions underlying their forecasting models, for example, constant versus time-varying parameters and linear versus non-linear forecasting models, etc. Faced with multiple forecasts of the same variable, an issue that immediately arises is how best to invest information in the individual forecasts.

Specifically, should a single dominant forecast be identified or should a combination of the underlying forecasts be used to produce a pooled summary measure? From a theoretical perspective, unless one can identify in advance a particular forecasting model that generates smaller forecast errors than its competitors (and whose forecast errors cannot be covered by other models), forecast combinations offer diversification gains that make it attractive to combine individual forecasts rather than relying on forecasts from a single model. Even if the best model could be identified at each point in time, combination may still be an attractive strategy due to diversification gains, although its success will depend on how well the combination weights can be determined. Forecast combinations have been used successfully in empirical work in such diverse areas as forecasting gross national product, currency market volatility, inflation, money supply, stock prices and meteorological data.

\section{Research Problem}

The problem of the study is that the process of integration of predictions considered a complex statistical process; therefore, the study tries use different weight method to apply the integration process to the models resulting from use of the vector autoregressive approach in different techniques. Furthermore, this study shows some economic time series such as unemployment rates, economic growth rates, and the general 
government expenditure series . The previously mentioned series affect one another through using VAR and SVAR models.

\section{Objectives of the study}

The main objective of this study is Measuring the Accuracy of Forecasting Using Integrated VAR models economy. This objective is divided into several sub-objectives:

1. To use the VAR method to estimate a model that can be used to measure the relationship between unemployment rates, economic growth rates, and general government expenditure.

2 . To evaluate the performance of the forecasts resulting from use of VAR models and evaluate the performance of integration forecasts resulting from use of weights integration methods. 3. To perform simulations of VAR models and compare their results with actual data results from the time series used.

\section{Delimitations of the study}

1- This study used three variables to apply the practical study represented in three times series (unemployment rates, economic growth rates and general government expenditure).

2- The study was limited in the applied phase on the years from 1995 to 2016 because lack of data before this period.

3- The study was limited in calculating the economic growth rate on the income criterion, which is considered the main criterion in the calculation of the rate of economic, and the study did not address the other criteria such as health, educational and social standards because of its difficulty .

4- The study was limited to use some methods of the vector autoregressive such as : SVAR, VAR, VARX and Simulation of VAR. 


\section{Hypothesis of the study}

1. The study assumes that the VARX method is the best statistical model used.

2. The study assumes that the weights integration method is better and more accurate than the normal method of those previous statistical models.

\section{Literatures Review}

This study tries to establish a causal relationship between the nominal exchange rate and foreign direct investment in India using a time series data between 1992 and 2010. It tries to understand whether the fluctuation in the exchange rate in turn causes the change in the quantum of foreign direct investments inflows and vice-versa, which is of enormous importance in the wake of unprecedented depreciation of Indian Rupee against US dollar. Unit root test and Johenson cointegration test are used to show whether the variables under consideration exhibit stationarity and a long run association respectively (Raju \&Gokhale , 2012).

The test indicates absence of any long-term association between the two variables under consideration. In this context, it appears that the data is not stationary at level and is stationary at first difference. The Vector Autoregression (VAR) model depicts that the coefficients do not have any long run association. The results they obtained show Chi square value with probability of 0.5246 and 0.4622 respectively indicating that the variables jointly cannot influence the dependent variable. Hence, they see that there is no statistical evidence for the quantum of FDI investments into India to be dictated by the trends in nominal Exchange rate. The exchange rate fluctuation essentially does not impair the quantum of foreign direct investment. It can be assumed that inward flow of direct investment is independent of exchange rate volatility. However, the first lag and second lag of the foreign direct investment exhibits a significant relationship between the foreign direct investments indicating that the lagged FDI could be responsible for attracting FDI in the subsequent year (Raju \& Gokhale, 2012).

Artis and zhang (1990) conducted forecasts, derived from Bayesian vector autoregressive models, for the output growth, inflation and balance of payments of the G-7 countries. In constructing the models, particular attention is paid to the determination of the prior and to the choice of lag length and vector content. The forecasts derived from the models are compared with those published by the International Monetary Fund on alternative assumptions about the information set available to the forecaster. The results indicate that BVAR methods can provide a highly 
effective standard of comparison for forecasts produced by more traditional methods. The work reported in this paper has been directed at constructing alternative Bayesian vector autoregressive (BVAR) models for forecasting variables of interest for the leading industrial economies (Artis \& zhang, 1990).

Two six-equation models were developed, differing in respect of vector content, and were set to produce ex ante forecasts for 1980- 1987, using Kalman filtering techniques to update the estimation with the passage of time. Comparison of Theil statistics demonstrated the superiority of the BVAR model over univariate AR and unrestricted VAR models. However, the BVAR models must be 'tuned' correctly to achieve such results; inappropriate priors could yield less clear cut conclusions (Artis \& zhang, 1990).

The forecasting performance of the BVAR models was then compared with that of the forecasts produced by the International Monetary Fund and published in the World Economic Outlook (WEO). These forecasts appear to be comparable in quality with the general run of economic predictions so that the relative performance of the BVAR models against the WEO can be taken to be broadly representative. The comparisons indicate that in overall terms the BVAR models set a tough standard of comparison for forecasts produced by more traditional methods. Tuning the comparison to achieve exact equivalence in information sets is not feasible with the data available, and it is apparent that 'small' changes in the information assumption can change the ranking of the forecasts. Forecasts derived from BVAR models appear to provide an impressively high and comparatively cheap standard of comparison for international by more traditional methods (Artis \& zhang , 1990).

The researchers concluded with a note concerning the sensitivity of our forecasting results to their prior. Given the close correspondence of their prior and posterior estimates of the parameters of the theoretical model, the potential sensitivity of their predictive densities to the adoption of alternative priors is nontrivial. But as the close correspondence between the posterior and likelihood quantiles depicted illustrates, the prior does not exert undo influence on the predictive densities in this case. In particular, the relatively tight prior the researchers specified over the parameters of the theoretical model induced very little shrinkage beyond that induced by the adoption of the theoretical model (Dejong et al.,2002).

They have proposed the use of a coherent statistical framework for formally bringing to bear theoretical models of dynamic macroeconomic activity in addressing empirical issues of interest to policy makers, forecasters, and practitioners interested in explaining the behavior of 
observed data. The framework is Bayesian for a given theoretical model ; it involves combining the likelihood function induced by the model with a prior distribution specified over the model's parameters, and using the resulting posterior distribution to address empirical questions of interest. Of interest to Dejong et al. (2002) in this application was the ability of a neoclassical business cycle model to generate accurate forecasts of the cyclical behavior of output and investment. Ability has been demonstrated in this case ; the performance of the model is comparable to that of a Bayesian VAR, a result we find to be impressive. Measurement with theory appears to have its merits.

From the previous presentation of the studies related to the subject of the study, there is a lack of studies to study all the static and dynamic approaches of the VAR models together, and therefore there is a clear lack of studies. Accordingly, the study will adopt this important research point ( i.e. the static and dynamic methods of time series using the Vector Auto Regressive method).

Multivariate time series methods are widely used by empirical economists and econometricians. The methods highly contributed to refining and extending these techniques so that they are well suited for answering economic questions. Multivariate time-series analysis extends many of the ideas of univariate time-series analysis to systems of equations. The primary model in multivariate time-series analysis is the vector autoregression (VAR) a direct and natural extension of the univariate autoregression. Most results that apply to univariate time - series can be directly ported to multivariate time-series with a slight change in notation and the use of linear algebra, including (VAR analysis, cointegration and spurious regression). This chapter discusses the properties of vector timeseries models, estimation and identification as well as Granger causality and Impulse Response Functions. Vector autoregressions are remarkably similar to univariate autoregressions ; too similar that the intuition behind most results carries over by simply replacing scalars with matrices and scalar operations with matrix operations. 


\section{Combining Forecasts Method}

\section{Forecast combinations}

Combining point forecasts to improve forecast performance goes back at least to the work of Bates and Granger (1969) who combined two separate sets of forecasts of airline passenger data to form a composite set of forecasts. Combination has gained popularity since forecasters want to draw valid model inferences and discarded forecasts nearly always contain some useful independent information. The independent information can be of two kinds.

First, a discarded forecast can be based on variables that are not featured in the chosen forecast model. Second, the discarded forecast makes a different assumption about the form of the relationship between the variables (Bates \& Granger, 1969). The second case in particular does not necessarily lead to a situation in which a combined forecast improves upon the better individual forecast.

\section{Equal weights (EW)}

Equal weights were introduced by Bates and Granger (1969) and are the simplest forecast combination method. Although combined forecasts where the individual forecasts are given equal weights acceptable for illustrative purposes, one wishes to give greater weights to the set of forecasts that contain the lower mean squared errors.

However, equal weights for point forecast combination have often proven to be better than more sophisticated weighting schemes when the robustness of the forecast combinations is tested pseudo out of sample.

Formally,

$$
w_{t+h \mid t}^{(i)}=(E W)=\frac{1}{N} \forall t, h \text { and } i .
$$

Where: $i$ denotes an individual model,

$N$ The number of models,

$h$ The forecast horizon 


\section{Mean Squared Error Weights (MSEW)}

The concept of ranking models with respect to their relative mean squared prediction error performances computed over a window of previous observations was also introduced by Bates and Granger (1969).

These MSE weights are not optimal in a linear framework since MSE weights ignore the correlation structure between forecasts but tend to outperform the more sophisticated weighting schemes since the correlation matrix of the forecast errors is quite difficult to estimate.

Weights derived from the relative inverse mean squared error of an individual model $i$ for the $h$ step ahead point forecast take the following form:

Where:

$$
w_{t+h \mid t}^{(i)}=\frac{1 / M S E_{t h \mid t}^{(i)}}{\sum_{j=1}^{N} 1 / M S E_{t+h \mid t}^{(j)}}
$$

$$
M S E_{t+h \mid t}^{(i)}\left(Y_{t+h \mid t}^{*}\right)=\frac{1}{t-h-\underline{t}+1} \sum_{T=\underline{t}}^{t-h}\left(Y_{T+h}-Y_{t+h \backslash t}^{*(i)}\right)^{2}
$$

Letter $\underline{t}$ is the beginning of the evaluation period -1 while $h, t, i$ $N$ have the same interpretation as for equal weights.

\section{Akaike Information Criteria Weights (AICW)}

Akaike weights are derived from the Akaike information criteria (AIC) which Hirotsugu Akaike proposed in his seminal paper (Akaike, 1973). The main idea of this information criteria is to use the Kullback - Leibler (K-L) information (distance) as a fundamental basis for model selection. The (K-L) distance cannot however, be computed without full knowledge about the data generating process and the parameters of all the candidate models, which is never the case when we forecast economic variables.

To calculate the Akaike weights, The researchers needs to calculate the AIC values for the individual models. To do that we must define the empirical log likelihood $\left(\Lambda_{i}\right)$ at its maximum point for modeli . Formally:

$$
\Lambda_{i}=\left(\frac{T_{i}-p_{i}}{2}\right)\left(\log \left|\widehat{\Omega}_{i}^{-1}\right|-n \log \left(2 \prod\right)-n\right)
$$


Where:

$$
\widehat{\Omega} \equiv\left[\begin{array}{ccc}
\operatorname{var}\left(\hat{\epsilon}_{1}^{i}\right) & \operatorname{cov}\left(\hat{\epsilon}_{1}^{i}, \hat{\epsilon}_{2}^{i}\right) & \operatorname{cov}\left(\hat{\epsilon}_{1}^{i}, \hat{\epsilon}_{n}^{i}\right) \\
\operatorname{cov}\left(\hat{\epsilon}_{1}^{i}, \hat{\epsilon}_{2}^{i}\right) & \operatorname{var}\left(\hat{\epsilon}_{2}^{i}\right) & \operatorname{cov}\left(\hat{\epsilon}_{n-1}^{i}, \hat{\epsilon}_{n}^{i}\right) \\
\operatorname{cov}\left(\hat{\epsilon}_{1}^{i}, \hat{\epsilon}_{n}^{i}\right) & \operatorname{cov}\left(\hat{\epsilon}_{2}^{i}, \hat{\epsilon}_{3}^{i}\right) & \operatorname{var}\left(\hat{\epsilon}_{n}^{i}\right)
\end{array}\right]
$$

$A I C_{i}$ then becomes:

$$
\text { AIC }_{i}=-2\left(\Lambda_{i}\right)+2 K_{i}
$$

With $\widehat{\Omega}_{i}$ being the variance - covariance matrix for model $i, T_{i}-p_{i}$ being the length of the original data sample minus the lag length of the VAR, $n$ represents the number of variables in the system and $K_{i}$ is the number of parameters estimated in the system including the intercepts and the variances - covariances. So instead of estimating the $K-L$ distance between two models, one estimates the expected distance between the fitted model and the unknown true mechanism that actually generated the observed data. To calculate the weight for model $i$ it is common to compute, for each model, the differences in AIC with respect to the AIC of the best candidate model .

$$
\Delta_{i}(A I C)=\left[A I C_{i}-\min (A I C)\right],
$$

Where min $(A I C)$ is the smallest value of $A I C$ in the model set. The best model is the one with lowest $A I C$ value / highest maximized log likelihood. It's important to notice that these differences are calculated for models from the same model class, vintage and forecasting step $h$. So the equation above can be written as:

$$
\Delta_{t+h \mid t}^{(i)}=\frac{\exp \left\{-\frac{1}{2} \Delta_{t+h \mid t}^{(i)}(A I C)\right\}}{\sum_{j=1}^{N} \exp \left\{-\frac{1}{2} \Delta_{t+h \mid t}^{(j)}(A I C)\right\}}
$$

Where $N$ is the number of models and $h, t, i$ have the same definitions as before. The AIC weights above are written in a general form, but are used as in-sample weights in this project (based on the in-sample performance of the models). The AIC weights are, therefore, not re-estimated for every forecast step, but estimated for every vintage for each individual model and multiplied with all of the out-of-sample point forecast that the individual model $i$ creates, so all forecast steps $h$ are assigned the same weight within a vintage. This is also the case for BIC weights. The in-sample AIC weight for the individual model $i$ can be written as: 


$$
w_{t}^{i}(A I C)=\frac{\exp \left\{-\frac{1}{2} \Delta_{t}^{i}(A I C)\right\}}{\sum_{j=1}^{N} \exp \left\{-\frac{1}{2} \Delta_{t}^{j}(A I C)\right.}
$$

Although the $A I C^{\prime} S$ are used to weigh models instead of using it to select the lag length of the VAR's and hence the choose the most parsimonious models, an AIC weighting scheme may still have some advantages over a weighting scheme which uses the equal model weights since it assigns the heaviest weight to the individual model within a class that has the highest maximized log likelihood (AIC $\mathrm{min}$ ) if the models have the same number of parameters.

\section{Bayesian Information Criteria Weights (BICW)}

To calculate Bayesian Information Criteria (BIC) weights $\Lambda_{i}$ calculated in the same manner as for the AIC , but the penalty term for the BIC is different.

$$
\begin{gathered}
B I C_{i}=-2\left(\Lambda_{i}\right)+K_{i} \log \left(T_{i}-p_{i}\right) \\
\text { And } \Delta_{i}(B I C)=\left[B I C_{i}-\min (B I C)\right]
\end{gathered}
$$

Just as raw AIC values may be converted to Akaike weights, raw BIC values can be converted to BIC model weights (or Schwarz weights). Schwarz weights can be obtained by replacing the AIC with BIC in the $w_{i}$ equation above:

$$
w_{t}^{i}(B I C)=\frac{\exp \left\{-\frac{1}{2} \Delta_{t}^{i}(B I C)\right\}}{\sum_{j=1}^{N} \exp \left\{-\frac{1}{2} \Delta_{t}^{j}(B I C)\right\}}
$$

This can be done through setting equal 'reference' prior probabilities on the individual models in each class where prior probability for model $i$ is set to equal $\frac{1}{N}$ for all models where $N$ is still the number of models in each model class.

Although the equations of AIC and BIC look very similar, they originate from quite different frameworks. The BIC assumes that the true model for forecasting is in the set of candidate models, and it measures the degree of belief that a certain model is the true data-generating model. The AIC does not assume that any of the candidate models is necessarily true, but rather estimates for each model the Kullback Leibler discrepancy, which is a measure of distance between the probability density generated by the model and reality. The Bayesian information criteria also favors simple 
models (i.e., those with fewer parameters) to a greater extent than AIC favors.

\section{Model Combination}

\section{Model Solution}

It requires using the estimated coefficients above to predict all the endogenous variables. Also, it allows for the consideration of different scenario analysis. Eviews 9 programme will be used .

\section{Simulation types}

\section{- Deterministic Simulation}

It involves solving the model without simulating the residuals. In addition, all the estimated coefficients are used in the simulation at their point estimates likewise all the exogenous variables are held constant.

\section{- Stochastic Simulation}

The equations in the model are solved and simulated with residuals. Also, the coefficients and exogenous variables of the model are varied randomly. For stochastic simulation, the model solution generates a distribution of outcomes for the endogenous variables in every period. The researcher approximas the distribution by solving the model many times using different draws components in the model then calculating statistics over all the different outcomes.

\section{Solution Types}

\section{- Static Solution}

It is usually used when dealing with in-sample simulation where the predicted values of the endogenous variables in model can compared with the historical data. This requires using the actual values of all the explanatory variables (both exogenous and lagged endogenous variables of the model).The predictive ability of the model can be evaluated based on the in-sample simulation. 


\section{- Dynamic Solution}

This is the solution for Out-of-Sample Simulation. We have to forecast all the exogenous variables. Statistically, there are different approaches of forecasting time series ranging from the Naive, Simple Average, Simple Moving Average, Weighted Moving Average, Trend Projection to Exponential Smoothing methods. These methods are briefly discussed below.

\section{Algorithm Approaches}

It is essentially the algorithm used to solve the model. In this study, there are three approaches of solving a model period. They are:

- Gauss-Seidel: This is an iterative algorithm, where at each iteration we solve each equation in the model for the value of its associated endogenous variable, treating all other endogenous variables as fixed. The Gauss-Seidel less computationally demanding when compared to other methods and it performs well on most econometric models.

- Newton: This algorithm can handle a wider class of problems than GaussSeidel, but requires considerably more working memory and has a much greater computational cost when applied to large models.

- Broyden: This is modification of Newton's method (often referred to as a quasi-Newton or secant method) and requires iterations to converge to a solution than the Newton. However, the Broyden spends less than the time required to solve the model by Newton's model.

\section{VARX Model (1)}

1. Deterministic simulation - static solve -1990:2010- solver: Gauss- Sediel - max iteration 1000 -scenario: Baseline will be used .

2. Making graph to compare the baseline and actual. 


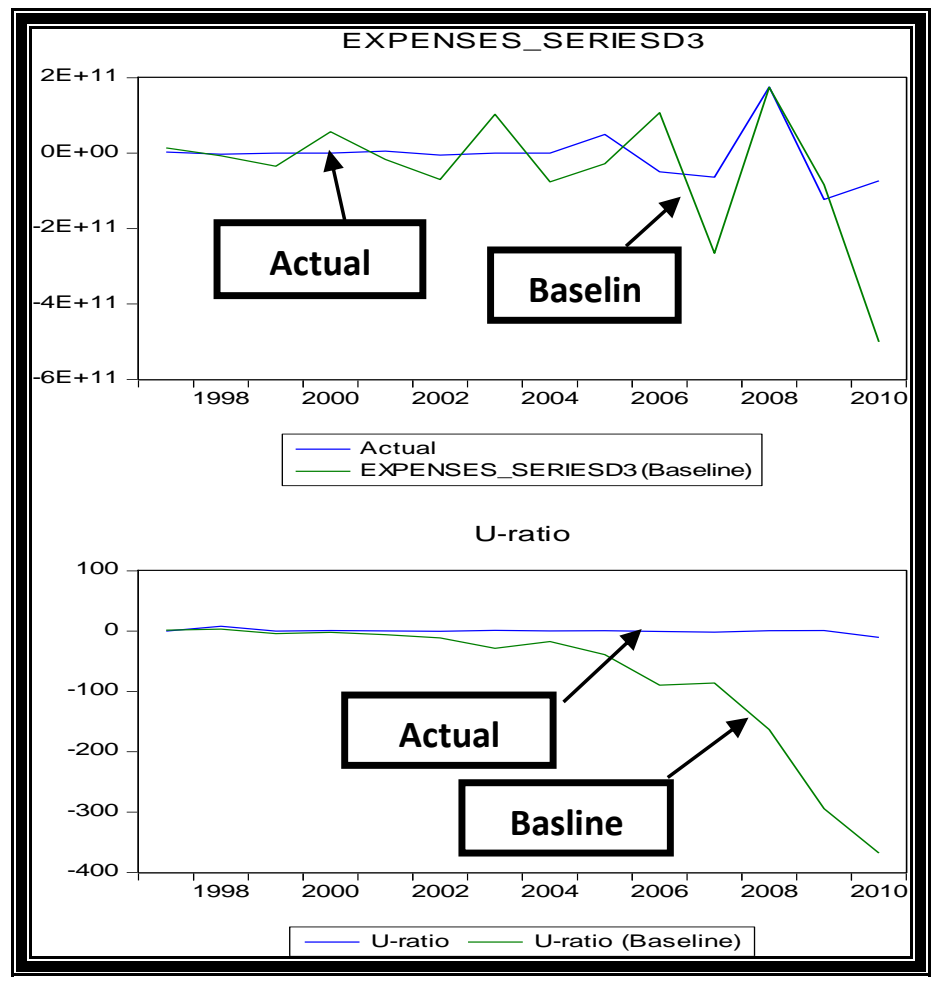

Figure (1) Model Solution of VARX model (1) graph

3. The table denotes static-Deterministic solution and it distinguishes the baseline from the actual.

4.

Table (1) static -Deterministic solution to estimations with VARX model (1)

\begin{tabular}{|c|c|c|}
\hline Years & Expenses-Baseline & Unemployment-Baseline \\
\hline $\mathbf{1 9 9 7}$ & 13832400000 & 1.658508 \\
\hline $\mathbf{1 9 9 8}$ & -7053486000 & 3.295760 \\
\hline $\mathbf{1 9 9 9}$ & -34912970000 & -4.213209 \\
\hline $\mathbf{2 0 0 0}$ & 56895460000 & -1.973297 \\
\hline $\mathbf{2 0 0 1}$ & -16546520000 & -5.816478 \\
\hline $\mathbf{2 0 0 2}$ & -70248840000 & -11.37043 \\
\hline $\mathbf{2 0 0 3}$ & 102818700000 & -28.61591 \\
\hline $\mathbf{2 0 0 4}$ & -76460170000 & -17.39162 \\
\hline $\mathbf{2 0 0 5}$ & -28201670000 & -39.03900 \\
\hline $\mathbf{2 0 0 6}$ & 107044700000 & -89.64356 \\
\hline $\mathbf{2 0 0 7}$ & -265711800000 & -85.98131 \\
\hline $\mathbf{2 0 0 8}$ & 174518000000 & -163.3141 \\
\hline $\mathbf{2 0 0 9}$ & -84079100000 & -294.2515 \\
\hline $\mathbf{2 0 1 0}$ & -500820800000 & -367.9939 \\
\hline
\end{tabular}

5. The researcher uses deterministic simulation- Daynamic solve - 2011-2016 solver: Gauss- Sediel - max iteration 1000 -scenario: Baseline. 
6. Making graph to compare the baseline and actual to out-of-sample simulation.

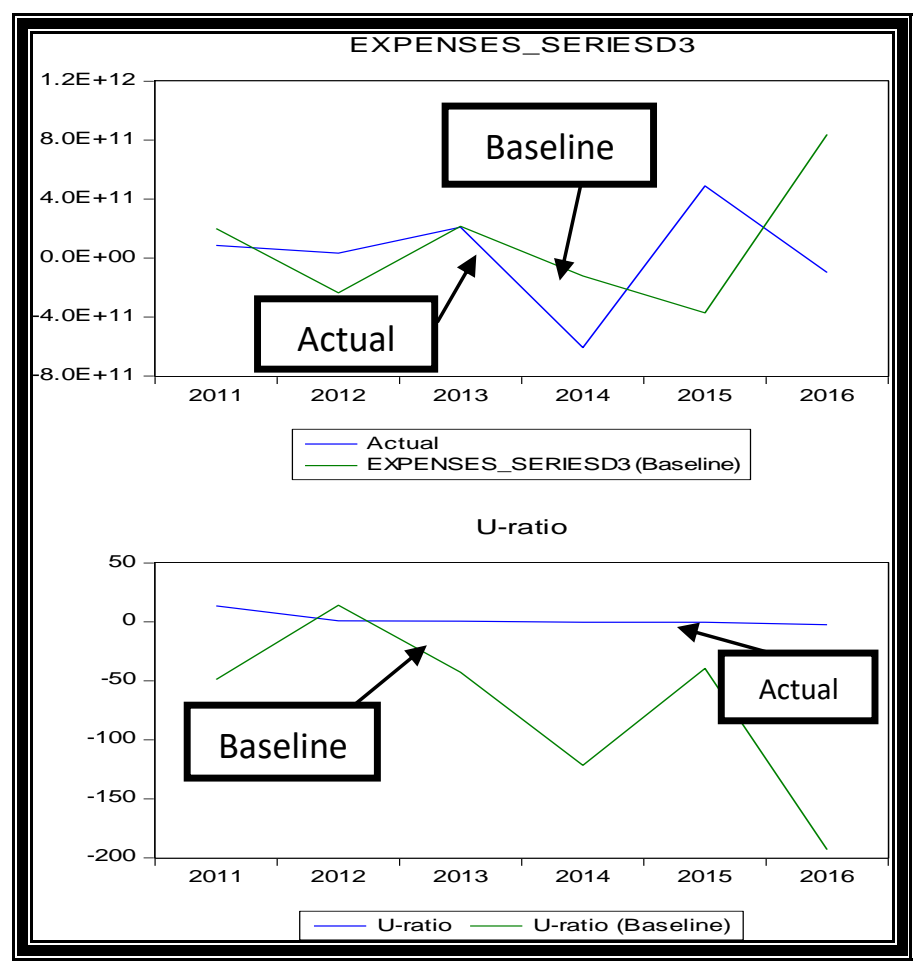

Figure (2) Forecasts Solution of VARX model (1) graph

7. Another table denotes Dynamic -Deterministic solution to forecasts from 2011 to 2016:

Table (2) Dynamic Deterministic solution to forecasts with VARX model (1)

\begin{tabular}{|c|c|c|}
\hline Years & Expenses-Baseline & Unemployment-Baseline \\
\hline 2011 & 199744500000 & -48.72524 \\
\hline 2012 & -236538300000 & 14.23206 \\
\hline 2013 & 215474700000 & -42.72105 \\
\hline 2014 & -121392500000 & -121.6722 \\
\hline 2015 & -371415100000 & -39.35380 \\
\hline 2016 & 838440300000 & -193.1495 \\
\hline
\end{tabular}


VARX Model (2)

1. The researcher uses deterministic simulation - static solve -1990:2010solver: Gauss- Sediel - max iteration 1000 -scenario: Baseline.

2. Making graph to compare the baseline and actual.

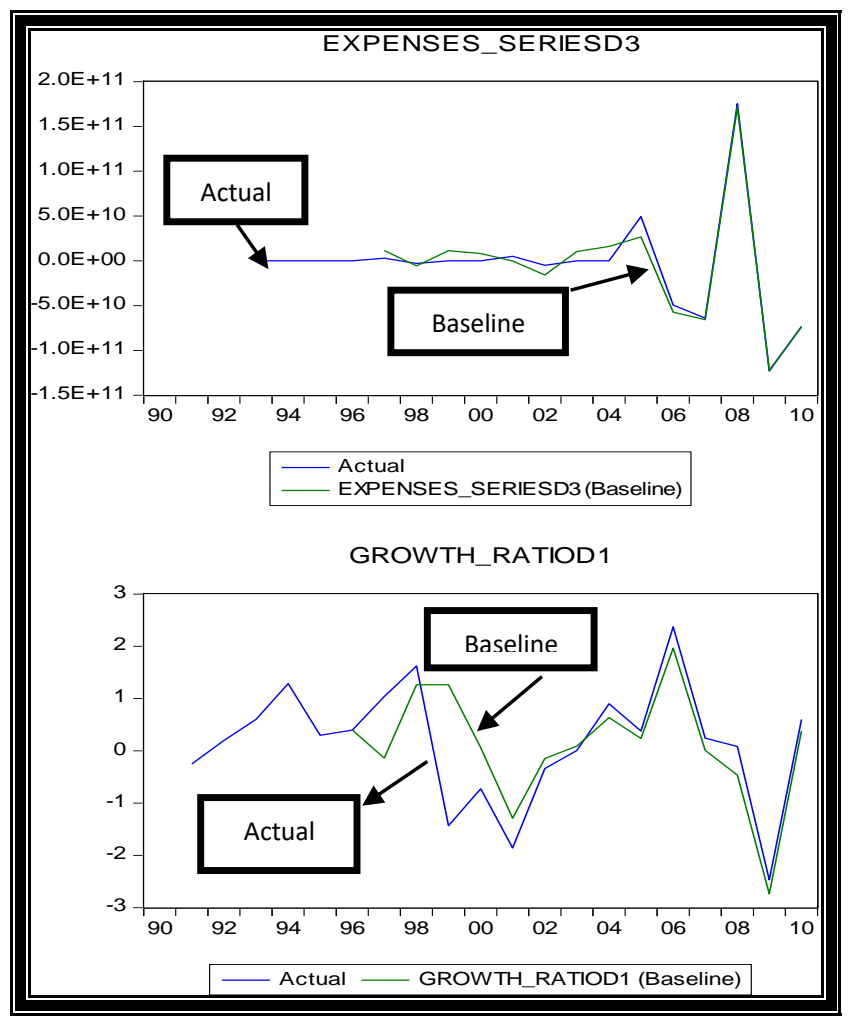

Figure (2) Model Solution of VARX model (2) graph

3. The table denotes static-Deterministic solution and it distinguishes the baseline from the actual.

Table (3) static-Deterministic solution to estimations with VARX model (2)

\begin{tabular}{|c|c|c|}
\hline Years & Expenses-Baseline & Growth-Baseline \\
\hline $\mathbf{1 9 9 7}$ & $1.14 \mathrm{e}+10$ & 0.395000 \\
\hline $\mathbf{1 9 9 8}$ & $-5.57 \mathrm{e}+09$ & 1.265858 \\
\hline $\mathbf{1 9 9 9}$ & $1.12 \mathrm{e}+10$ & 1.265858 \\
\hline $\mathbf{2 0 0 0}$ & $8.17 \mathrm{e}+09$ & 0.0619255 \\
\hline $\mathbf{2 0 0 1}$ & $-1.48 \mathrm{e}+08$ & -1.291534 \\
\hline $\mathbf{2 0 0 2}$ & $-1.60 \mathrm{e}+10$ & -0.1464925 \\
\hline $\mathbf{2 0 0 3}$ & $1.04 \mathrm{e}+10$ & 0.0901549 \\
\hline $\mathbf{2 0 0 4}$ & $1.60 \mathrm{e}+10$ & 0.6352476 \\
\hline $\mathbf{2 0 0 5}$ & $2.67 \mathrm{e}+10$ & 0.2356853 \\
\hline $\mathbf{2 0 0 6}$ & $-5.73 \mathrm{e}+10$ & 1.965508 \\
\hline $\mathbf{2 0 0 7}$ & $-6.58 \mathrm{e}+10$ & 0.0117305 \\
\hline $\mathbf{2 0 0 8}$ & $1.71 \mathrm{e}+11$ & -0.4647126 \\
\hline $\mathbf{2 0 0 9}$ & $-1.22 \mathrm{e}+11$ & -2.736941 \\
\hline $\mathbf{2 0 1 0}$ & $-7.36 \mathrm{e}+10$ & 0.3834021 \\
\hline
\end{tabular}


4. The researcher uses deterministic simulation- Daynamic solve 20112016 solver: Gauss- Sediel - max iteration 1000 -scenario: Baseline.

5. Making graph to compare the baseline and actual to out-of-sample simulation.

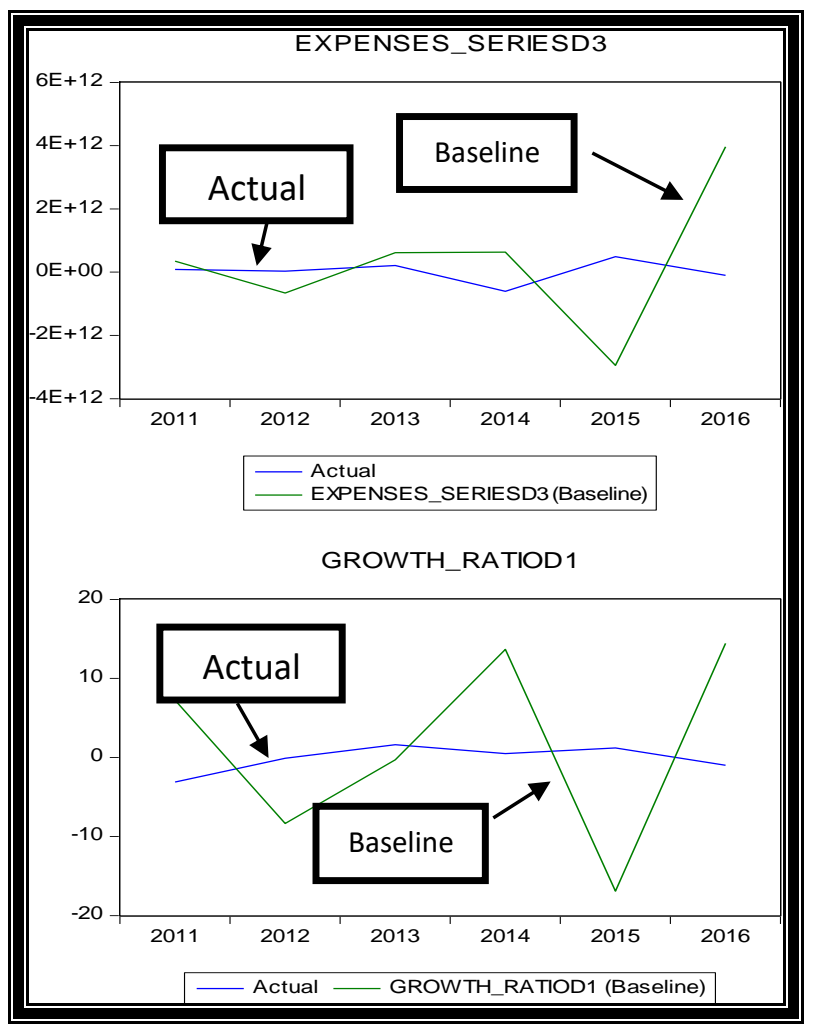

Figure (3) Forecasts Solution of VARX model (2) graph

8. Another table denotes Dynamic -Deterministic solution to forecasts from 2011 to 2016.

Table (4) Dynamic Deterministic solution to forecasts with VARX model (2)

\begin{tabular}{|c|c|c|}
\hline Years & Expenses-Baseline & Growth-Baseline \\
\hline 2011 & 348799400000 & 7.238098 \\
\hline 2012 & -660772900000 & -8.356232 \\
\hline 2013 & 612732000000 & -0.300133 \\
\hline 2014 & 630650200000 & 13.66168 \\
\hline 2015 & -2946289000000 & -16.90452 \\
\hline 2016 & 3967191000000 & 14.44206 \\
\hline
\end{tabular}


This part estimates of the proposed models for studying and predicting values for these models and then move on to integrate these models with their own ways to incorporate predictions and will appear in the next part.

\section{Combining Models with Weights Method}

In this part of the study, as we mentioned previously, that the models reached will be combined (i.e VARX(1) and VARX(2)) Thus, through the use of the methods of incorporating the predictions, the following are mentioned:

\section{First Method (Equal-weight)}

The previous two models were combined by using the Eviews program. It is a special programme that has been worked out for them to implement the combination. This method assumes that the weights that are given for each model are equal and the weights used for both models are extracted through the following formula and applied within its own program.

$$
w_{t+h \mid t}^{(i)}=(E W)=\frac{1}{N} \forall t, h \text { and } i .
$$

Where: $i$ denotes an individual model,

$N$ The number of models,

$h$ The forecast horizon

\section{Second Method (Mean squared error weights)}

In this method, weights have been determined for the two models by using another method which is MSEW According to the following formula:

$$
w_{t+h \mid t}^{(i)}=\frac{1 / M S E_{t+h \mid t}^{(i)}}{\sum_{j=1}^{N} 1 / M S E_{t+h \mid t}^{(j)}}
$$

\section{Third Method (Akaike information criteria weights)}

This method is more complex than the previous methods where it is calculated from the standard AIC calculated for each model and weights are determined according to the following mathematical formula:

$$
w_{t}^{i}(A I C)=\frac{\exp \left\{-\frac{1}{2} \Delta_{t}^{i}(A I C)\right\}}{\sum_{j=1}^{N} \exp \left\{-\frac{1}{2} \Delta_{t}^{j}(A I C)\right.}
$$




\section{Fourth Method ( Bayesian information criteria weights )}

This method is almost similar in the calculation of the previous method AIC, but it depends on the value of the Max log likehood Calculated for both models and the weights used for the two models are also determined by the application of the following mathematical law:

$$
w_{t}^{i}(B I C)=\frac{\exp \left\{-\frac{1}{2} \Delta_{t}^{i}(B I C)\right\}}{\sum_{j=1}^{N} \exp \left\{-\frac{1}{2} \Delta_{t}^{j}(B I C)\right\}}
$$

From the previous results, the built - in series are grouped into a single table as follow :

Table (5) Combining Series

\begin{tabular}{|c|c|c|c|c|}
\hline Years & $\boldsymbol{Y}_{\text {equal }}$ & $\widehat{Y}_{\text {Mse }}$ & $\widehat{Y}_{\text {AIC }}$ & $\widehat{Y}_{\text {BIC }}$ \\
\hline 1993 & 0.309000 & 0.051079 & $2.17 \mathrm{e}+19$ & 0.599929 \\
\hline 1994 & 0.645000 & 0.075092 & $4.43 \mathrm{e}+19$ & 1.287843 \\
\hline 1995 & 0.149500 & 0.019653 & $1.03 \mathrm{e}+19$ & 0.295964 \\
\hline 1996 & 0.186000 & 0.000758 & $1.20 \mathrm{e}+19$ & 0.394949 \\
\hline 1997 & $3.00 \mathrm{E}+09$ & $3.00 \mathrm{E}+09$ & $3.01 \mathrm{e}+29$ & $3.00 \mathrm{e}+09$ \\
\hline 1998 & $-3.00 \mathrm{E}+9$ & $-3.00 \mathrm{E}+09$ & $-3.01 \mathrm{e}+29$ & $-3.00 \mathrm{e}+09$ \\
\hline 1999 & -0.766500 & -0.175764 & $-5.57 \mathrm{e}+19$ & -1.432837 \\
\hline 2000 & 0.086500 & 0.807526 & $3.43 \mathrm{e}+19$ & -0.726802 \\
\hline 2001 & $5.01 \mathrm{E}+09$ & $5.01 \mathrm{E}+09$ & $5.01 \mathrm{e}+29$ & $5.10 \mathrm{e}+09$ \\
\hline 2002 & $-5.01 \mathrm{E}+09$ & $-5.01 \mathrm{E}+09$ & $-5.01 \mathrm{e}+29$ & $-5.10 \mathrm{e}+09$ \\
\hline 2003 & 0.638500 & 1.198215 & $8.38 \mathrm{e}+19$ & 0.007154 \\
\hline 2004 & 0.600000 & 0.334045 & $5.06 \mathrm{e}+19$ & 0.898927 \\
\hline 2005 & $4.95 \mathrm{E}+10$ & $4.95 \mathrm{E}+10$ & $4.95 \mathrm{e}+30$ & $4.95 \mathrm{e}+10$ \\
\hline 2006 & $-4.95 \mathrm{E}+10$ & $-4.95 \mathrm{E}+10$ & $-4.95 \mathrm{e}+30$ & $-4.95 \mathrm{e}+10$ \\
\hline 2007 & $-6.41 \mathrm{E}+10$ & $-6.41 \mathrm{E}+10$ & $-6.41 \mathrm{e}+30$ & $-6.41 \mathrm{e}+10$ \\
\hline 2008 & $1.75 \mathrm{E}+11$ & $1.75 \mathrm{E}+11$ & $1.75 \mathrm{e}+31$ & $1.75 \mathrm{e}+11$ \\
\hline 2009 & $-1.23 \mathrm{E}+11$ & $-1.23 \mathrm{E}+11$ & $-1.23 \mathrm{e}+31$ & $-1.23 \mathrm{e}+11$ \\
\hline 2010 & $-7.34 \mathrm{E}+10$ & $-7.34 \mathrm{E}+10$ & $-7.35 \mathrm{e}+30$ & $-7.34 \mathrm{e}+10$ \\
\hline 2011 & $3.49 \mathrm{E}+11$ & $3.49 \mathrm{E}+11$ & $3.49 \mathrm{e}+31$ & $3.49 \mathrm{e}+11$ \\
\hline 2012 & $-6.61 \mathrm{E}+11$ & $-6.61 \mathrm{E}+11$ & $-6.61 \mathrm{e}+31$ & $-6.61 \mathrm{e}+11$ \\
\hline 2013 & $6.13 \mathrm{E}+11$ & $6.13 \mathrm{E}+11$ & $6.13 \mathrm{e}+31$ & $6.13 \mathrm{e}+11$ \\
\hline 2014 & $6.31 \mathrm{E}+11$ & $6.31 \mathrm{E}+11$ & $6.31 \mathrm{e}+31$ & $6.31 \mathrm{e}+11$ \\
\hline 2015 & $-2.95 \mathrm{E}+12$ & $-2.95 \mathrm{E}+12$ & $-2.95 \mathrm{e}+32$ & $-2.95 \mathrm{e}+12$ \\
\hline 2016 & $3.97 \mathrm{E}+12$ & $3.97 \mathrm{E}+12$ & $3.97 \mathrm{e}+32$ & $3.97 \mathrm{e}+12$ \\
\hline & & & & \\
\hline
\end{tabular}

From this previous presentation, we have 6 new predictive series estimated:

$\widehat{Y}$ individual(1) $\widehat{Y}$ individual(2) $\widehat{Y}_{\text {Equal }}$ combined $\widehat{Y}_{M S E}$ combined $\hat{Y}_{A I C}$ combined $\hat{Y}_{B I C}$ combined 
Their forecast capability is then chosen through the following prediction test criteria: RMSE , MSE , MAPE, MAE, Theil test

The results are summarized as follows :

Table (6) Forecasts Criteria with Real Data

\begin{tabular}{|c|c|c|c|c|}
\hline & RMSE & MAE & MAPE & Thiel \\
\hline$\hat{Y}_{1}$ & 52.963 & 40.5189 & $4.49 \mathrm{E}-09$ & $1.28 \mathrm{E}-11$ \\
\hline$\hat{Y}_{2}$ & 46.9541 & 35.922 & $3.98 \mathrm{E}-09$ & $1.13 \mathrm{E}-11$ \\
\hline$\hat{Y}_{\text {equal }}$ & 45.8139 & 36.1133 & $3.61 \mathrm{E}-09$ & $1.11 \mathrm{E}-11$ \\
\hline$\hat{Y}_{\text {MSE }}$ & 92.3727 & 72.0353 & $7.59 \mathrm{E}-09$ & $2.23 \mathrm{E}-11$ \\
\hline$\hat{Y}_{\text {AIC }}$ & 29.55689 & 23.54401 & $2.23 \mathrm{E}-09$ & $7.13 \mathrm{E}-12$ \\
\hline$\hat{Y}_{\text {BIC }}$ & 11.5617 & 10.1432 & $1.08 \mathrm{E}-09$ & $2.79 \mathrm{E}-12$ \\
\hline
\end{tabular}

Through previous values, the forecast ability of each model is judged. Note from the previous table showing the criteria for evaluating the forecasts that the combined model using the method (Bayesian information criteria weights) (BICW) are the best methods used to combine forecasts to give them the best results they have in them.

At the end of this section, it can be concluded that the method of combining forecasts based on the BIC weights is the best predictive method by applying them to models the scrap of raw data for models VARX(1) VARX(2), so as to give it the lowest values for both RMSE, MAE, MAPE, Theil test. The next part will generate random data and apply all the above in detail and make a comparison showing the methods used.

\section{RESULTS AND RECOMMENDATIONS}

This study has reached a number of results, which should be introduced in the economic and statistical fields. These findings and recommendations will be presented as follows :

\section{Results}

(1) The study has shown statistically that government public expenditure is an endogenous of statistical analysis since it has had an impact on the statistical model. The more government spending on the development of the small system, as well as the concern for the health of individuals, the 
greater the development of society and hence economic growth rates and declining unemployment rates.

(2) The study has shown that using the VAR model with all variables of study as an endogenous variable is a statistically insignificant model.

(3) The significance of the VARX models has been clarified from the study by using two different models: The first model uses the government public spending series and economic growth rates as endogenous variables and consider variable unemployment rates as an exogenous variable. Model Two it is the use of the government public spending series and the unemployment rate series as endogenous variables and the consideration of economic growth rates as an exogenous variable but through the use of the two models have proven the statistical significant models.

(4) The study demonstrated the ability of combined models to predict better than normal models by traditional methods through their application to actual data.

(5) The study has shown that combined models using the BICW method are the best combining methods used to integrate forecasts through their application to actual data.

(6) The study has shown that the combined models using weights are better than normal models in their predictive accuracy.

The study ends with some general recommendations that may be taken into account .

\section{RECOMMENDATIONS}

(1) The study recommends that the Egyptian economy grow attention to the rates of economic growth and investment and increase the values of public expenditure in the above-mentioned areas, as this will in turn lead to a decline in unemployment rates.

(2) The study recommends that statisticians use the combined models using weights to improve the forecast capability of time series, as they yield better results than normal models of their high forecast capability. 
(3) The study recommends using the BICW (Bayesian information criteria weights) as it gives its compact models the best forecast capability.

\section{References}

1. Akaike, H., (1973), Information theory and an extension of the maximum likelihood principle. In: International Symposium on Information Theory, 2 ND, Tsahkadsor, Armenian SSR. pp. 267-281.

2. Andersson ,M.K. , Karlsson, S., (2007) Bayesian forecast combination for VAR models .

3. Artis, M.J \& Zhang, W.(1990) BVAR forecasts for the G-7, International Journal of Forecasting , 6.

4. Asteriou, D. and Stephen G.Hall (2007) , Applied Ecnometrics, Revised Edition.

5. Bahgat $M$. Thabet, (1995), Forecasting in time series (improving forecasts by means of combination) A survey International ISSR, Cairo University.

6. Bates, J., and C. Granger (1969), The Combination of Forecasts, Operations Research Quarterly, 20, 451-468.

7. Bernanke, B.S. (1986): Alternative explanations of the Money-Income Correlation, Carnegie-Rochester Conference Series on Public Policy, 25, 49-99.

8. BRATU,M.(2012) , COMBINING FORECASTS BASED ON ECONOMETRIC MODELS FOR SHORT RUN MACROECONOMIC PREDICTIONS WITH HIGH DEGREE OF ACCURACY, The USV Annals of Economics and Public Administration, Volume 12, Issue 2(16).

9. Casals, J. , Garca-Hiernauxy , A. \& Jerez , M. (2010), From general State-Space to VARMAX models.

10. David N. DeJong, Beth F. Ingram, Charles H. Whiteman (2002) , A Bayesian approach to dynamic Macroeconomics, Journal of Econometrics .

11. DICKEY, D. A., AND W. A. FULLER , (1979), "Distribution of the Estimators for Autoregressive Time Series With a Unit Root," Journal of the American Statistical Association, 74, 366, 427-431.

12. Doan, T., Robert Litterman, and C. Sims (1984), "Forecasting and conditional projection using realistic prior distributions," Econometric Reviews.

13. Eklund, J., Karlsson, S., (2007), Forecast combination and model averaging using predictive measures. Econometric Reviews 26.

14. Eliot, G., Rothenberg, T.J. \& Stock, J.H. (1996) ,Efficient Test for an Autoregressive unit root. Econometrica, 64 ( 4):813 -836.

15. Eltony, M. , Al-Awadi , M. (2001) " Oil price fluctuations and their impact on the macroeconomic variables of Kuwait: a case study using a VAR model", INTERNATIONAL JOURNAL OF ENERGY RESEARCH , Int. J. Energy Res, 25:939959 .

16. Engle, R.F., Granger, C.W.J., (1987), Co-integration and Error Correction. Representation, Estimation and Testing. Econometrica 55, 251]276. 
17. Pfaff, B. , (2008), VAR, SVAR and SVEC Models: Implementation Within R Package vars .

18. Sandu , C.\& Ghiba , N. (2011), THE RELATIONSHIP BETWEEN EXCHANGE RATE AND EXPORTS IN ROMANIA USING A VECTOR AUTOREGRESSIVE MODEL, Annales Universitatis Apulensis Series Oeconomica, 13(2) .

19. Spencer, D. (1993), Developing a Bayesian vector autoregression forecasting model , International Journal of Forecasting , 9 .

20. Helmut Lutkepohl (2005), New introduction to multiple time series analysis , ,Springer.

21. Sharifi-Renani , H. (2010), Vector Autoregressive Analysis of Economic Growth, International Trade and Environment in Iran, International Conference on Economics, Business and Management .

22. Ryšánek , J. (2010), COMBINING VAR FORECAST DENSITIES USING FAST FOURIER TRANSFORM.

23. Jonathan H. Wright, (2008), Bayesian Model Averaging and exchange rate forecasts, Journal of Econometrics,146 (2008) 329341.

24. J.V. Raman Raju \& Mayuresh S. Gokhale (2012) , Empirical Analysis of the Causal Relationship between Nominal Exchange Rate and Foreign Direct Investment in India using VAR (Vector Autoregression Model) , Global Journal of Management and Business Research, VOL 17 Issue 22.

25. Kalliovirta , L. , Meitz , M. , Saikkonen , P. (2014), Gaussian mixture vector autoregression, Helsinki center of Economic Research .

26. Ooms, M. (1994) , Empirical Vector Autoregressive Modeling, Springer-Verlag.

27. Po-Hsuan Hsu, Wang, C. , Joseph Z. Shyu, Hsiao-Cheng Yu, A Litterman (2002), BVAR approach for production forecasting of technology industries, Technological Forecasting \& Social Change .

28. Schwarz, G., (1978), Estimating the dimension of a model. The Annals of Statistics 2 .

29. Simkins, S. (1995), Forecasting with vector autoregressive (VAR) models subject to business cycle restrictions, International Journal of Forecasting 11.

30. Sims, C.A. (1980), "Macroeconomics and Reality," Econometrica.

31. SONALI DAS, GUPTA, R. , \& KABUNDI , A. (2011), Forecasting Regional House Price Inflation: A Comparison between Dynamic Factor Models and Vector Autoregressive Models, Journal of Forecasting.

32. Taiwo .A .I , Olatayo T.O (2013), Measuring Forecasting Performance of Vector Autoregressive and Time Series Regression Models, AMERICAN JOURNAL OF SCIENTIFIC AND INDUSTRIAL . 
